\title{
Lead Isotope Analysis for Picogram Size Samples by TE-DS-TIMS using Amplifier equipped with $10^{13} \mathrm{Ohm}$ Resistor
}

\author{
Y. FUKAMI ${ }^{1 *}$, M. TOBITA ${ }^{2}$, T. YOKOYAMA ${ }^{2}$ AND \\ K. SUZUKI ${ }^{3}$ \\ ${ }^{1}$ Dept. Chem., Gakushuin Univ., Tokyo, 171-8588, Japan \\ (*correspondence: yusuke.fukami@gakushuin.ac.jp) \\ ${ }^{2}$ Dept. Earth Planet. Sci., Tokyo Tech, Tokyo, 152-8851, \\ Japan \\ ${ }^{3}$ JAMSTEC, Yokosuka, 237-0061, Japan
}

The total evaporation (TE) method is suitable for measuring isotope ratios of small-scale samples using TIMS. The combination of TE-TIMS with the ${ }^{204} \mathrm{~Pb}-{ }^{207} \mathrm{~Pb}$ double spike method (TE-DS-TIMS) achieved a precision of $0.37 \%$ (2SD) for ${ }^{206} \mathrm{~Pb} /{ }^{204} \mathrm{~Pb}$ ratio in the repeated measurement of 0.5 ng of NIST 981 [1]. To further reduce the requisite sample amount in the $\mathrm{Pb}$ isotope measurement with TE-DS-TIMS, the use of amplifiers equipped with high resistance resistors $\left(10^{12}\right.$ or $\left.10^{13} \Omega\right)$ would be preferred [2]. Although such high resistance amplifiers are effective to improve the signal/noise ratio during $\mathrm{Pb}$ isotopic analysis, their signal response is much slower than that of the normal, low resistance amplifier $\left(10^{11} \Omega\right)$ [3].

This study aims to evaluate the influence of the different signal response for high $\left(10^{13} \Omega\right)$ and low $\left(10^{11} \Omega\right)$ resistance amplifiers in the $\mathrm{Pb}$ isotope measurement with TE-DS-TIMS. To this end, 100 and $10 \mathrm{pg}$ of NIST $981 \mathrm{~Pb}$ were repeatedly measured with TE-DS-TIMS $\left({ }^{204} \mathrm{~Pb}-{ }^{207} \mathrm{~Pb}\right.$ double spike) using TRITON plus at JAMSTEC, with the following amplifier settings: (a) $10^{11} \Omega$ for all isotopes, (b) $10^{13} \Omega$ for ${ }^{204} \mathrm{~Pb}$ and $10^{12} \Omega$ for the other isotopes.

In spite of the difference in the signal response, $\mathrm{Pb}$ isotope ratios measured by the setting (b) were consistent with those measured by (a) within the analytical uncertainties. The precisions (2SD) of ${ }^{206} \mathrm{~Pb} /{ }^{204} \mathrm{~Pb}$ ratio measured by (b) were $0.59 \%$ and $1.2 \%$ for the measurement using $100 \mathrm{pg}$ and $10 \mathrm{pg}$ of NIST 981, respectively. For the measurement of $10 \mathrm{pg}$ of $\mathrm{Pb}$, the precision was improved by approximately 14 times compared to that for setting (a). Therefore, no correction for the response time is needed in the analytical setting (b) in which two types of amplifiers with different signal response are simultaneously used for the $\mathrm{Pb}$ isotope measurement with TE-DS-TIMS.

[1] Fukami et al., 2014, J. Anal. At. Spectrom., 32, 848-857.

[2] Koornneef et al., 2014, Anal. Chim. Acta, 819, 49-55. [3]

Kimura et al., 2015, J. Anal. At. Spectrom., 31, 790-800. 